\title{
MANAGING THE DUST DEGREE -RELATED RISKS IN VALEA JIULUI COLLIERIES: A SYNTHESIS
}

doi: $10.2478 /$ czoto-2021-0015

Date of submission of the article to the Editor: $30 / 11 / 2020$

Date of acceptance of the article by the Editor: 2/03/2020

\section{Florin-lonel Burdea ${ }^{1}$}

Roland-losif Moraru² - orcid id: 0000-0001-8629-8394

1 University of Petroşani, Romania

${ }^{2}$ University of Petroşani, Romania

\begin{abstract}
The paper aims to make a synthesis regarding the risks associated with the presence of industrial dust in the underground atmosphere of the coal mines. Thus, in the first part of it are presented relevant aspects regarding the health risk associated with the exposure to silica dust, as well as the flammability and explosiveness of the coal dust, in correlation with the mechanism of the explosion. The second part is dedicated to identifying and substantiating measures to combat the explosiveness of coal dust. In presenting the mentioned measures, the emphasis is placed on highlighting the scope and the specific advantages and disadvantages of each measure, with particular emphasis on the possibilities offered by the use of less employed techniques in mining operations in the Jiu Valley, such as it is, for example, the treatment of mining works with hygroscopic substances. The purpose of the authors is to offer the experts in the field of management of occupational safety and health in the mining industry an overview, in conjunction with specific information elements that facilitate the decision-making processes regarding the minimization of the hazards associated with the degree of coal dustiness in the Jiu Valley collieries.
\end{abstract}

Keywords: dustiness, health risk, explosion hazard, prevention, minimization technique.

\section{INTRODUCTION}

The government, regulatory authorities and their agencies aim to improve occupational safety and health in order to reduce the costs of work-related injuries and occupational diseases incurred by the mining companies, while improving national competitiveness and efficiency (Romanian Parliament, 2006). Safety and health at work can contribute to increased productivity by reducing the number of people who retire early or who cannot work due to personal injury or work-related illness, by reducing the costs of medical care and social costs of accidents and diseases, by increasing people's work capacity, by improving their health and productivity, stimulating the most efficient working methods and techniques (Darabont 
and Pece, 1996; Moraru and Băbuţ, 2000).

Improvement of the coal mining technique, by introducing modern cutting and supporting equipment, has led, among other things, to the intensification of the dust formation phenomenon in underground mining works. The dust resulting from the process of extracting the useful mineral substance, dust existing at the work places either in suspension or in the form of deposits, presents a double hazard for the personnel that carry out this activity: i) a health hazard, by the fact that after a certain period of activity it can produce the occupational illness by pneumoconiosis; ii) an explosion hazard, knowing that at a certain amount of dust, in the presence of favorable factors and of an ignition source, can trigger explosions with particularly negative effects, both social and economic, well known - unfortunately - at the level of the Jiu Valley coal basin (Băbuţ and Moraru, 1999; Moraru and Băbuţ, 2000; Stassen, 1981 )

\section{HEALTH RISK. PROPERTIES OF SILICA DUST AND FACTORS DETERMINING THE HARMFULNESS ASSOCIATED WITH EXPOSURE}

Dust can be defined as a finely divided solid substance which, depending on the size of the particles, their concentration and composition, if present at workplaces, either in suspension or in the form of deposits, presents a double hazard for personnel (Voicu, 1988):

i. a health hazard, as it may induce after a certain period of exposure the occupational disease of the staff by pneumoconiosis;

ii. an explosion hazard, knowing that at a certain amount of combustible dust (airborne or settled), in the presence of favorable factors (the presence of methane) and a source of ignition, it can trigger explosions with catastrophic effects.

These hazards are known for a long period of time, a fact confirmed by the sustained efforts made to study how they are produced, how they behave in the environment, how they are measured and how they are mitigated (Moraru et al., 2011).

In this sense, to define the dust and the extent to which it is present in the atmosphere, several parameters or combinations thereof have been used; the most important are: i). number of particles per unit volume; ii) particle distribution according to their size; iii). the amount of dust related to the volume unit; iv). dust surface per volume unit; v). the chemical composition; vi). the mineralogical nature.

The first four parameters depend not only on how the dust is formed, but also on the physical properties of the particles in its composition. The property that has a direct influence on the behavior of the dust in the atmosphere is the particle size distribution, because the size depends both on their duration of stay in suspension, and on the manner in which they will be deposited on the walls or floor of the mine working. The rate of dust deposition also depends on the velocity of the air currents. Thus, in the case of the laminar flow regime, the dust particles, within certain size limits, will be deposited with a constant sedimentation rate, corresponding to Stokes's law. These limits include the sizes of particles that are of greatest interest for the underground activity, namely 0.5-40 $\mu \mathrm{m}$ (Berceanu, 1972).

In the case of turbulent flow regime, the motion of the particles cannot be predicted and their removal from the air currents will be caused more by striking than by deposition. When small dust particles come into contact, they come together and separate very hard. The cohesion forces that give rise to this type of attachment are very small and, 
because of this, they are efficient for the particles with dimensions of the order of microns. In very dense dust clouds, many particles collide with each other due to Brownian motion, the resulting coagulation may lead to a decrease in suspended dust concentration (Băbuţ, 2012).

Inhaling the airborne dust, especially the one with dimensions below $5 \mu \mathrm{m}$, is extremely harmful to the health of the underground personnel and leads to the occurrence of occupational diseases known as pneumoconiosis. Depending on the nature of the dust that caused them, they know different names such as: silicosis, anthracosis (caused by coal dust), baritosis, talcosis, asbestosis etc. The most serious of these is silicosis caused by silicon dioxide that attacks the lung tissue forming nodules. So far, the action of silicon dioxide on the human body has not been completely elucidated. In this sense, several theories have been issued (Băbuţ, 2012):

- the mechanical theory, which assumes that quartz dust irritates the lung due to the sharp edges of the respective particles;

- the solubility theory, which assumes that silicon dioxide dissolves in liquids of a biological nature and converts into silicic acid that acts on tissues;

- the theory of crystal surface activity, which assumes that on the surface of freshly broken crystals there are free valences that have a high affinity to bind and thus a more intense biological activity.

However, it is certainly and unanimously recognized that the main factors that contribute to the occurrence of pneumoconiosis among miners are (Matei et al, 2000):

- the mineralogical composition of the rocks in which the mining works are executed;

- the concentration of airborne dust in the workplace atmosphere;

- the size (degree of fineness) of the airborne dust particles;

- the duration of personnel exposure.

Regarding the situation existing in the mining operations in the Jiu Valley, in table 1 are presented some suggestive data in this regard.

Table 1

The average $\mathrm{SiO}_{2}$ content [\%] characteristic for the rocks in the Jiu Valley basin

\begin{tabular}{|c||c|c|}
\hline $\begin{array}{c}\text { Crt. } \\
\text { no. }\end{array}$ & Rock type & Average SiO $_{2}$ content [\%] \\
\hline \hline 1 & Sandstones & $26-90$ \\
\hline 2 & Greasy clays & $10-27$ \\
\hline 3 & Clays & $1.0-10$ \\
\hline 4 & Clays and marls & $1.0-3.0$ \\
\hline 5 & Marls & $1.0-1.7$ \\
\hline 6 & Coal shale & $1.3-3.0$ \\
\hline 7 & Coal seam 3 & $2.5-8.0$ \\
\hline 8 & Coal seam 4 & $1.5-2.5$ \\
\hline 9 & Coal seam 5 & $0.5-7.5$ \\
\hline 10 & Coal seam 8-9 & $1.8-2.5$ \\
\hline 11 & Coal seam 13 & $1.5-3.5$ \\
\hline 12 & Coal seam 17-18 & $4.5-9.0$ \\
\hline
\end{tabular}

Source: (Bitir and Kovacs, 1980) 
Medical research on subjects affected by silicosis revealed that the dust retained in the lungs is generally below $7 \mu \mathrm{m}$ and in an amount ranging from $0.25 \mathrm{~g}$ to $5-15 \mathrm{~g}$, depending on the nature and characteristics specific to inhaled dust, the percentage representing maximum 1-2\% of the total inhaled dust. Much of the dust amount inhaled is eliminated through the human body's self-defense mechanism (Teodorescu et al., 1980).

\section{RISK OF EXPLOSION. INFLUENCE FACTORS AND ACTION PARAMETERS}

\subsection{Influence factors}

The explosiveness of coal dust is conditioned by a complex of factors, of which the most important are discussed bellow, based on primary testing (Baron and Krausz, 1997):

\section{a. Content in volatile matter}

The explosive capacity of coal dust increases rapidly to a volatile matter content of 25$35 \%$; after which this capacity decreases, almost as rapidly as it has grown. This explains the fact that in some types of coal, such as anthracite (which has a low volatile matter content, $1-2 \%$ ), the danger of dust explosion is extremely low. It may also be mentioned that volatile matter is not an element of particle-to-particle explosion transmission in the dust cloud. Due to their incandescence, they change the surface of the coal particles in relation to their coking properties, becoming an indirect cause of process evolution.

\section{b. The degree of fineness}

The degree of fineness is the ratio between the amount of dust passing through the $0.075 \mathrm{~mm}$ sieve $\left(\mathrm{C}_{0.075}\right)$ and the total amount of dust $(\mathrm{C} 1)$ with particles passing through the $1 \mathrm{~mm}$ sieve.

$$
G_{f}=\frac{C_{0,075}}{C_{1}} \cdot 100 \quad[\%]
$$

The explosiveness of the dust with the same content of volatile materials increases with the degree of fineness up to a certain limit, because the specific surface of the coal increases with the degree of fineness. The explosiveness no longer depends on the degree of fineness if $70-90 \%$ of the amount of dust passes through the $0.06 \mathrm{~mm}$ sieve, because a fine particle agglomeration tendency appears. The ignition temperature of the coal dust decreases as the fineness increases.

\section{c. Degree of dispersion}

The airborne dust concentration is variable in time and space and represents the amount of dust related to the volume unit. There is a minimum value of this parameter, the minimum explosive concentration or the lower explosion limit, below which the explosion cannot propagate. Above the upper explosion limit, the dust acts by the thermal inertia of the particles, the radiation dissipated by the combustion of a particle is absorbed by a large number of surrounding particles that cannot raise their temperature enough to take place, a similar phenomenon to the inhibition with extinguishing powders. The explosive limits of the coal dust vary in a quite wide area (table 2). Theoretically, the maximum intensity explosion in the case of pure carbon occurs at a concentration of $112 \mathrm{~g} / \mathrm{m}^{3}$, but experimental research has shown that, in the case of coal dust, the maximum dynamic effect occurs at concentrations between $100-300 \mathrm{~g} / \mathrm{m}^{3}$. 
Table 2

Explosive limits of coal dust

\begin{tabular}{|c|c|c|c|}
\hline \multirow{2}{*}{ Conditions } & \multicolumn{3}{|c|}{ Limit explosion concentration $\left[\mathbf{g} / \mathbf{m}^{3}\right]$} \\
\cline { 2 - 4 } & Lower & $\begin{array}{c}\text { Maximum intensity } \\
\text { explosion }\end{array}$ & Upper \\
\hline \hline Laboratory tests (experimental) & $18-30$ & $100-300$ & $2000-3000$ \\
In-situ tests (practical conditions) & $100-120$ & - & - \\
\hline
\end{tabular}

Source: (Gontean et al, 1987)

\section{d. Content in non-combustible materials}

Ash content, along with moisture content, is a heat inhibiting factor during dust explosions. The higher the ash content in the coal dust, the higher the ignition temperature of the dust cloud is required, and the minimum explosive concentration must be higher. V. Cybulski has established that the explosion does not occur at a concentration of $70-80 \%$ (firedamp mines) of non-combustible materials (Cybulski, 1973).

\section{e. Petrographic constitution}

The petrographic constitution influences the explosiveness of the dust by the different behavior of the petrographic components, as well as their characteristics (gas and ash content, specific weight, etc.) (Petrescu, 1987). The vitrite is the most hazardous component. The fusite is the least dangerous, because although it has a tendency to break higher than vitrite, it contains lesser volatile matter and has a lot of ash. It has been established that, in mining operations in the Jiu Valley, from a petrographic point of view, coal dust contains vitreous (kaolinite and telinite) 15-72\%, clarit (exinit, resinit and mertite), 21-84\%, fusite which appears sporadically and mineral components (pyrite, marcasite, calcite, gypsum and clay). We notice the presence, in large quantities, of the most dangerous components (vitrite and clarite) and a particularly low contribution of the non-dangerous component (fusite) (Knebel, 1991).

\section{f. Moisture content}

Coal dust is considered neutralized when it contains at least $30 \%$ water. This influence is characteristic in the explosion priming phase. During the propagation of the explosion, moisture content can no longer play the role of a determinant inhibitor due to the large amount of generated heat.

\section{g. The presence of methane}

The presence of methane greatly increases the risk of coal dust explosion, even when present in low concentrations. A percentage of methane that by burning releases 90 $\mathrm{kcal}$ is equivalent to about $12 \mathrm{~g}$ of coal (with a calorific value of $7500 \mathrm{kcal}$ ). For example, if the lower explosive limit of a coal dust is $40 \mathrm{~g} / \mathrm{m}^{3}$ and if $2 \% \mathrm{CH}_{4}$ is in the mixture, the lower explosive limit of the dust is reduced to $40-2 \cdot 12=16 \mathrm{~g} / \mathrm{m}^{3}$. For safety reasons, the lower explosive limit of coal dust is also determined by the addition of $2 \% \mathrm{CH}_{4}$.

\section{h. The nature and strength of the ignition source}

Also Cybulsky (1973) established the influence exerted on the triggering and transmission of the explosion factors such as temperature, flame velocity and shock strength, under different dust mining conditions. The stronger the source of initiation, the lower is the minimum explosive concentration. The most hazardous sources of ignition are methane gas explosions and blasting operations. 


\subsection{The explosive parameters of coal dust}

It is considered explosive coal dust "all the granules that passes through the sieve with mesh of $1 \mathrm{~mm}$ side and come from the coal seams that have a content higher than $10 \%$ volatile materials related to the fuel mass" (C.N.H. - S.A., 2007).

Explosiveness can be defined as representing the property of a substance that determines the level at which an explosion can be triggered under certain conditions and is characterized by the flammability and explosion parameters determined by laboratory methods. The mentioned parameters are presented in table 3 . Researches in the Romania (Knebel, 1998) and worldwide (Bracke, 1987) have shown that there is an almost perfect parallelism between the parameters of the methane explosions and coal dust explosions. In the case of coal dust explosions, the products of the explosion usually contain a higher amount of $\mathrm{CO}$, which can reach up to $5-6 \%$ (Knebel, 1996).

Table 3

Flammability and explosion parameters of combustible dusts

\begin{tabular}{|c|c|c|c|}
\hline $\begin{array}{l}\text { Crt. } \\
\text { no. }\end{array}$ & Parameter & Definition & Unit \\
\hline 1 & $\begin{array}{l}\text { Smoldering } \\
\text { temperature, TM }\end{array}$ & $\begin{array}{l}\text { Lowest temperature of a hot horizontal surface that } \\
\text { causes the appearance of the ember points on the } \\
\text { surface of a } 5 \mathrm{~mm} \text { thick powder layer, deposited by free } \\
\text { fall on that surface. }\end{array}$ & ${ }^{\circ} \mathrm{C}$ \\
\hline 2 & $\begin{array}{l}\text { Minimum ignition } \\
\text { temperature, TmA }\end{array}$ & $\begin{array}{l}\text { Lowest temperature of a source that causes the ignition } \\
\text { of airborne dust. }\end{array}$ & ${ }^{\circ} \mathrm{C}$ \\
\hline 3 & $\begin{array}{l}\text { Lower Explosion } \\
\text { Limit, CmEx }\end{array}$ & $\begin{array}{l}\text { The smallest amount of powder in relation to the unit } \\
\text { volume which ignites, in homogeneous mixture with the } \\
\text { air, in contact with a source of ignition. }\end{array}$ & $\mathrm{kg} / \mathrm{m}^{3}$ \\
\hline 4 & $\begin{array}{l}\text { Maximum } \\
\text { explosion pressure, } \\
P_{\text {e.max }}\end{array}$ & $\begin{array}{l}\text { The maximum of the winding curve of the explosion } \\
\text { pressures corresponding to the concentrations in the } \\
\text { explosive field. }\end{array}$ & $\mathrm{N} / \mathrm{m}^{2}$ \\
\hline 5 & $\begin{array}{l}\text { Maximum velocity } \\
\text { of explosion } \\
\text { pressure increase, } \\
\quad(\mathrm{dp} / \mathrm{dt})_{\max }\end{array}$ & $\begin{array}{l}\text { First derivative with respect to time at a given point of } \\
\text { the ascending branch of the explosion pressure variation } \\
\text { curve as a function of time. }\end{array}$ & $\mathrm{N} / \mathrm{m}^{2} \cdot \mathrm{s}^{-}$ \\
\hline 6 & $\begin{array}{l}\text { Minimum ignition } \\
\text { energy, } E_{\min }\end{array}$ & $\begin{array}{l}\text { Smallest energy amount of a spark capable of igniting } \\
\text { combustion in a dust-air mixture. }\end{array}$ & J \\
\hline
\end{tabular}

Source: (Knebel, 1996).

As illustrated graphically in Figure 1, the possibility of a coal dust explosion occurrence implies a simultaneous existence:

$>$ of the combustible substance - coal dust;

$>$ of the oxidizing agent - the oxygen in the atmospheric air;

$>$ of the ignition source. 


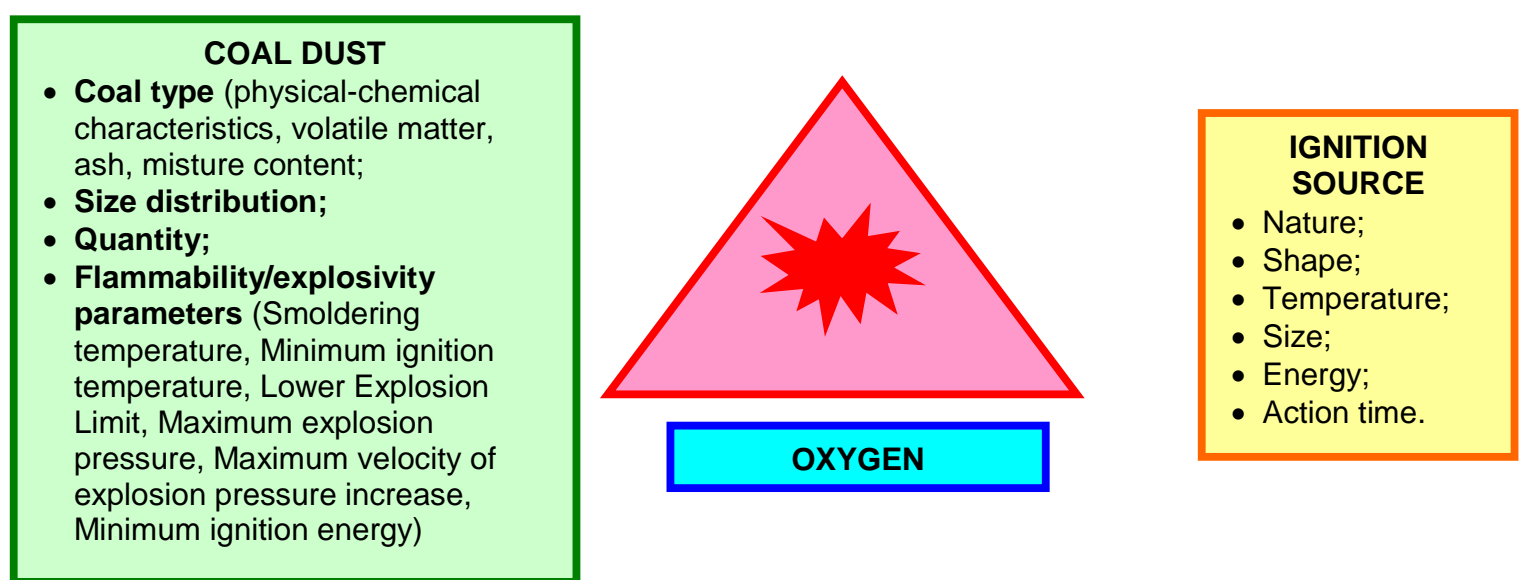

Fig. 1. The hazard triangle of the coal dust -air mixture

As the first of the above mentioned elements (coal dust) has already been dealt with in detail, the following will present some aspects regarding the other two components of the danger triangle.

A. Oxygen from the atmosphere of the technological space: the composition of the workspace atmosphere has a strong influence on the behavior of the coal dust in the process of ignition and explosion. The minimum oxygen concentration required to burn coal dust is $16 \%$. The presence of methane in the atmosphere or other flammable gases and vapors leads to sensitization of the ignition of coal dust, reducing the minimum explosive concentration up to 8 times that of fresh air. .

B. Sources of the dust-air mixture initiation: the cause of the explosion is the caloric energy yielded by the ignition source of the explosive medium. The most dangerous sources of coal dust explosions initiation are ignitions and explosions of flammable gases or vapors and improperly executed blasting operations with explosives, as they can simultaneously render dust airborne and can provide the minimum energy required to ignite the mixture. Spontaneous combustions, fires, flames, hot surfaces and ember may also be sources of explosion. There can be identified (Cârloganu, 1986):

- initiation sources that do not always ignite the air-dust mixture and are considered to be of rank $\mathbf{1}$ (e.g. some sparks);

- $\quad$ sources that almost always ignite the explosive mixture and which are of rank 2 (mechanical spark, hot surfaces, flames, fires, glowing points, welding pearls, electric arc, improperly executed blasting operations, gas explosions).

\subsection{Mechanism of the deployment and consequences of the coal dust explosions}

In the course of a coal dust explosion there are three phases in which the following physical-chemical processes take place (Winter and Giltaire, 1984):

\section{a. Coal particle pyrolysis, coal distillation or gasification}

The coal particles in the vicinity of the source, under the influence of heat absorbed, decompose releasing volatile substances. Volatile substances contain flammable gases and vapors (hydrocarbons, carbon monoxide, hydrogen, tar, etc.), carbon dioxide and water as vapors. The temperature rise velocity, the maximum temperature at which the particle reaches and the duration of the heating is a decisive factor in initiating explosions. Under experimental conditions it was found that in the 
case of hard coals the pyrolysis threshold is approximately $773 \mathrm{~K}$ and that volatile matter and especially tar have the ability to oxidize immediately after formation. In the case of bituminous coal, the pyrolysis threshold is lower $(623-673 \mathrm{~K})$ and the amount of volatile matter and tar is higher (Matei, 1991.).

\section{b. Burning of volatile substances - gas phase reactions}

Flammable gases and vapors form around the solid nucleus, in the presence of oxygen in the air, a sphere of flammable mixture. When the source energy is higher than the minimum ignition energy of the flammable mixture, it ignites after a period called reaction time. Reactions are complex, involving molecules of hydrocarbons, hydrogen, carbon monoxide, oxygen and various free atoms or radicals and intermediate products.

\section{c. Burning of the partially de-volatilized solid residue in the mixture}

The coal particle that went through the first two phases still contains a lot of volatile substances that are harder to release. The last phase is characterized by gas-solid reactions with the surrounding atmosphere and has a longer duration compared to the first two phases. The flame is propagated almost in close proximity of the gas mixture, the heat being transmitted by radiation to the environment that has not yet reacted. The explosion is self-propagating as long as there is enough coal dust available.

\section{MINIMIZATION TECHNIQUES FOR COAL DUST EXPLOSION HAZARD}

In mining works, coal dust deposits can accumulate in such quantities that by wrapping them they can form air mixtures at concentrations of tens of $\mathrm{g} / \mathrm{m}^{3}$ or even more. In order to minimize the hazard of explosion related to both settled and airborne coal dust, depending on the local conditions, one of the following methods is recommended to be applied:

$>$ dust removal;

$>$ suppression by water sprinkling;

$>$ neutralization with non-combustible substances;

$>$ treatment of mining works with hygroscopic substances.

Only the first three procedures are applied in practice in the Jiu Valley collieries.

\subsection{Dust removal}

The process of periodic removal of settled coal dust is applied, in particular, in the areas where it forms concentrated accumulations such as: rollers, overflows, spills, etc. Dust placed on machinery and electrical installations, especially in the area of the discharge points of the conveyor belts, should be removed daily. When removing the coal dust deposited on the walls and floor of the mining work, it is necessary to water spray it. The disadvantage of this simple technique is the relatively large workload, which makes it not practically applicable in most mining works.

\subsection{Dust stabilization with water}

In areas with high humidity, the deposited dust is considered neutralized if it does not have the possibility to rise in suspension or has reached saturation humidity. In case the neutralization of the deposited dust is done by spraying, the quantity of water required must ensure the saturation humidity of the dust (Bitir, 1982).

The efficiency achieved by fixing the dust deposited by splashing water depends not only 
on the amount of water used, but also on the drying time. The length of the drying time depends on a number of microclimate factors (air velocity, humidity and air temperature) and factors related to dust properties (grain size and coal nature). The properties of the coal that influence the wetting ability of the dust particles are: the degree of coal metamorphism, the type of the substances that determine the ash content, the humidity of the coal. This complex of factors that each act according to certain laws, in one way or another and interfere with each other, makes it difficult to interpret mathematically the physical phenomenon of dust wetting or drying. In this regard, the following aspects can be mentioned:

- the moisture content of the dust varies depending on the properties of the dust and the environment;

- the total humidity is inversely proportional to the degree of metamorphism;

- coals consisting mainly of carbon and hydrogen and containing very little colloidal bound water, are hydrophobic and their humidification is unsatisfactory;

- from the substances that give the ash content of coal, those that contain oxygen (for example, clay minerals) determine the moisture content of the dust;

- the particle size is an important factor: in the case of small fractions (below $0.5 \mathrm{~mm}$ ), the film water content is inversely proportional to the particle size;

- at the same time, in the case of fractions below $0.5 \mathrm{~mm}$ the pore volume is filled with water due to capillary forces; particle agglomerations result when moisture is at the lower limit required for pore filling (about 6-10\%).

In view of the above, the process of fixing the dust deposited by splashing with water has been systematically studied and it is authorized with very severe restrictions. Figure 2 schematically presents the results obtained from the tests regarding explosiveness determination of a coal dust with concentration initially determined with a known power ignition source.

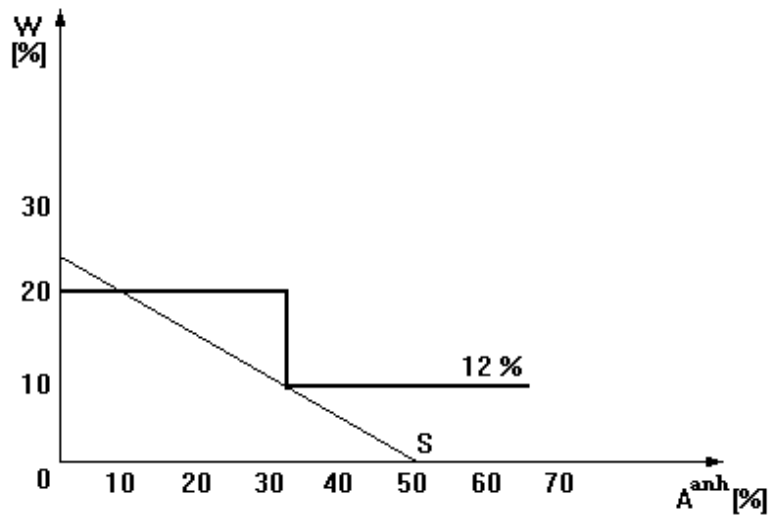

Fig. 2. Water neutralization

The straight line $S$ whose equation is given by the relation:

$$
S=A^{a n h}+K \cdot W
$$

share the plan $A^{\text {anh }}-W$ in two areas:

$I$ - area below the straight line $S$ in which the probability of coal dust explosion with properties $\left(A^{\text {anh }}, W\right)$ is high;

II - area above the straight line $S$ in which the probability of coal dust explosion with properties $\left(A^{\text {anh }}, W\right)$ is very low.

where: $\mathrm{W}$ is the total moisture content of dust coal, \%; $A^{\text {anh }}$ - the anhydrous ash content 
of coal dust, \%; $\mathrm{K}$ - factor that depends on the efficiency of the wetting process ( $\mathrm{K}=2$, for perfect wetting; $\mathrm{K}=1.3-1.5$, for average wetting); $\mathrm{S}$ - the equivalent degree of neutralization that ensures the same safety level as the coal dust with the properties $\left(A^{\text {anh }}, W\right)$ located on the straight line.

As long as the properties of the dust are constant, the $S$ value depends on the ignition source power and more or less the ease with which the dust can be dispersed by the blast of an explosion, thus $\mathrm{S}<40 \%$ for a coarse powder ignited by firing a charge of black powder into the mortar; $S>85 \%$ for a very easily dispersible dust that is initiated by the explosion of a methane-air mixture. At low values of $S$ (low intensity explosion), a humidity of dust is sufficient to prevent the lifting in suspension. In the event of a strong explosion, the dust is dried and dispersed by the blast and the heat generated by the explosion, the required amount of non-combustible substance (liquid or solid) being much higher than in the previous case. The value of $K>1$ shows that adding a percentage of water to wet dust is more effective than increasing the content of solid non-combustible substances by a certain percentage. It turns out that: at $W>20 \%$ humidity regardless of the amount of ash in the coal dust the probability of explosion is low; at $W>12 \%$ humidity and ash content of coal dust $A^{\text {Anh }}>35 \%$ also the probability of explosion is very low.

The diagram shows that for humidity and ash content above the thick line the hazard is minimal. In the mining practice it is difficult to permanently ensure the proper humidity of the dust. Splashing with water, although it has the greatest practical applicability due to its advantages (low cost price, ease of application), is nevertheless accompanied by the following disadvantages:

- by rapid evaporation of water and drying of dust deposits they again become hazard sources by their ability to rise in suspension;

- working conditions are worsening when dust humidity increases above certain limits;

- some types of coal dust do not get wet when sprayed with water, due to their high superficial tension $\left(72,8 \cdot 10^{-3} \mathrm{~N} / \mathrm{m}\right)$.

\subsection{Neutralization of coal dust by the addition of non-combustible substances}

The inert dust that is used for neutralization must meet a number of quality requirements. Upon neutralization, the inert dust is applied evenly throughout the contour of the mining work. The length of the neutralized area must be permanently at least $200 \mathrm{~m}$ from the dust generating sources. If the hazardous areas exceed $200 \mathrm{~m}$, further neutralization measures will be taken along the entire length of dust deposited, while the personnel must wear masks against dust. Neutralization by the addition of inert dust must ensure a content of non-combustible materials in the mixture of coal dust and inert dust of at least $80 \%$. The control of the neutralization, using the colorimetric method, is done in each shift by the supervisor (the manager of the team). The colorimetric standard sample is prepared by mixing coal dust with inert dust, in the proportion indicated by the relation:

$$
K=G \cdot \frac{N-A^{a n h}}{100-N} \quad[g]
$$

where: $\mathrm{K}$ is the amount of inert dust to be added to the coal dust sample, $\mathrm{g}$; $\mathrm{G}$ - coal dust amount used in the preparation of the colorimetric standard sample, $g ; A^{\text {anh }}$ - the ash content related to the anhydrous fuel of the initial coal dust sample, $\% ; \mathrm{N}$ - ash content 
relative to the anhydrous fuel of the standard sample,\%; $(\mathrm{N}=85 \%)$. The neutralization of coal dust with non-combustible substances has the disadvantage that it requires large quantities of material in the case of mining works with a high degree of dust.

\subsection{Treatment of mining works with hygroscopic substances}

Considering the disadvantages presented by the sprinkling of the deposited coal dust with water, methods of fixing the dust with hygroscopic salts have been experimented, applied, improved and regulated worldwide. Hygroscopic substances, absorbing moisture from the air, cause the uninterrupted humidification of the surface of the treated galleries and the fixing (binding) of the deposited dust. Given the fact that the coal dust is hygrophobic and is generally not sufficiently moistened, a surfactant product is added to the recipe. In order to achieve a sufficiently thick adhesion layer, a support substance (usually magnesium hydroxide) is added (Knebel, 1994.).

The most commonly used hygroscopic substances used for fixing coal dust in mining are: calcium chloride, magnesium chloride, sodium chloride. Calcium chloride is used in the form of paste, powder or sequins, and magnesium chloride in the form of paste. The paste is brought to the pumping stations or directly to the points of use in wagons with lid, specially arranged. With the help of a pump, paste is applied to the walls and roof of the gallery. The powder is applied with the aid of a blower or an ejector. The straws are spread with the shovel or with the help of compressed air. The application of the hygroscopic solution will be done on the entire contour of the mining work by a uniform spraying, following the absorption of the liquid on the coal seam. Splashing electrical equipment, metal construction elements and electrical cables with solution will be avoided. If in the mining work treated with hygroscopic salts for fixing the coal dust it is necessary to build dams, they will be dams with water. Spraying the hygroscopic solution on the deposited dust layer will be done in the sense of the air flow circulating in the mining work. When spraying solutions, workers will retreat behind the person performing the operation.

\section{CONCLUSIONS}

Creating and maintaining a safe and healthy work environment has been and is one of the main objectives of social policy at European and national level. The fulfillment of this objective is based on a better knowledge and understanding of the risks from the work places but also on the identification of the appropriate and effective measures of prevention / protection and of increasing the safety level. Without denying the elements of progress registered in recent years, namely the decrease in the number of work accidents and new cases of occupational disease by about $27 \%$, however, regarding fatal work accidents, the figures remain high.

From the study of the existing statistics it was found that in enterprises where the risk of explosion is present, explosions, whether or not followed by fires, are not the most frequent causes of accidents at work but their consequences are the most serious regarding the losses of human lives and economic damage. That is why an increasing emphasis is placed on the activity of explosion prevention and explosion protection which, in principle, is an old and well known activity, but the rigorous and consistent application of complex requirements raises the real problems: the efficiency of implementing very well- known principles about explosion protection and explosion risk reduction in mining industry.

The existence of a potential risk of explosion in the workplace also has implications 
for work organization. It is necessary to take organizational measures when applying only technical measures does not guarantee and does not maintain protection against explosions at work. In practice, the working environment can also be secured by a combination of technical and organizational measures to protect against explosions. The organizational measures determine the activity to be carried out in such a way that an explosion cannot generate damage for the workers. Also, the maintenance of technical measures to protect against explosions by inspection should be organized. Organizational measures should also take into account possible interactions between explosion protection measures and work organization. These combined explosion protection measures must allow workers to perform the assigned work tasks, without compromising the safety and health of them or other persons.

In underground working environments where explosive methane-air mixtures can be formed in concentrations that could endanger the safety and health of workers, adequate supervision, based on risk assessment, must be ensured.

\section{REFERENCES}

Baron, O., Krausz, I., 1997. Development of risk assessment procedures to establish measures to prevent explosions due to combustible gases, vapors and dusts (in Romanian, INSEMEX Petroşani Study.

Băbuţ, M.C., 2012. Ventilation, health and safety at work; laboratory supervisor, Focus Publishing House, Petroşani.

Băbuţ, G.B., Moraru, R.I., 1999. Labor protection, Universitas Publishing House, Petroşani.

Berceanu, L., 1972. Labor protection against methane, dust and radiation from the mine, Documentation and Publications Center of the Ministry of Labor, Bucharest.

Bitir, P., 1982 Increasing the efficiency of means of preventing and combating wet dust through the use of surfactants, Study I.S.M. Petrosani.

Bitir, P., Kovacs, L., 1980. Catalog of methods, means for preventing and combating dust. Apparatus for determining dust concentrations in air, C.C.S.M. Petrosani study.

Bracke, J., 1987. Comparative study of means of combating explosions in coal mines, Annales des Mines de Belgique, 2.

Cârloganu, C., 1986. Rapid combustion in dust and gases, Technical Publishing House, Bucharest.

C.N.H. - S.A., 2007. Occupational Health and Safety Regulations C.N.H. - S.A., Petroşani, 2007.

Cybulski, V., 1973. Coal dust explosions and their prevention, Slask Publishing House, Warsaw,.

Darabont, Al., Pece, Şt., 1996. Labor protection, Didactic and Pedagogical Publishing House, Bucharest.

Gontean, Z., Teodorescu, C., Neag, I., 1987. Ventilation and labor protection in the mine. Practical works, Lithography I.M.P..

Knebel, C., 1998. Contributions regarding the prevention and control of dust explosions, Doctoral thesis, University of Petroşani.

Knebel, C., 1991. Assessment of the potential explosion hazard of coal dust formed in the head galleries of frontal abutments, Study I.S.M. Petrosani.

Knebel, C., 1994. Study of the applicability of hygroscopic powders for capturing and fixing explosive dust in the mines from the Jiu Valley, INSEMEX Petroşani Study. 
Knebel, C., 1996. Contributions to the evaluation of the potential danger of coal dust explosion, Revista Minelor, 10-11.

Matei, I., 1991. Ventilation and labor protection in mining, Lithograph U.T. Petrosani.

Matei, I., Moraru, R.I., Samoilă, M., Băbuţ, G.B., 2000. Environmental engineering and underground ventilation, Technical Publishing House, Bucharest.

Moraru, R.I., Băbuţ, G.B., 2000. Risk analysis, Universitas Publishing House, Petroşani,.

Moraru, R.I, Băbuţ, G.B., 2000. Participatory risk assessment and management: practical guide, Universitas Publishing House, Petroşani, 2010.

Moraru, R.I., Băbuţ, M.C., Băbuţ, G.B., 2011. Ventilation, health and safety at work, Focus Publishing House, Petroşani.

Petrescu, I., 1987. Geology of coal deposits - vol. 2. Technical Publishing House, Bucharest.

Romanian Parliament, 2006. Occupational safety and health law no. 319/2006, Official Gazette of Romania, Part I, no. 646 / 26.07.2006.

Stassen, J.J., 1981. Dangers posed by explosive powders in coal mines and means of control, Annales des Mines de Belgique, 9.

Teodorescu, C., Gontean, Z., Neag, I., 1980. Mining aeration, Technical Publishing House, Bucharest.

Voicu, V., 1988. Air dedusting technique, Technical Publishing House, Bucharest.

Winter, J., Giltaire, M., 1984. Combating explosions of coal dust by neutralization and simultaneous use of dispersed water dams, Industrie Minerale - Les Techniques, nr. 7. 